\title{
Bulk Amorphous and Partially Crystallized Alloys in Nd-Fe-(Al, B) System with Hard Magnetic Properties Prepared by Arc Melting
}

\author{
Akira Takeuchi and Akihisa Inoue \\ Institute for Materials Research, Tohoku University, Sendai 980-8577, Japan
}

Bulk $\mathrm{Nd}_{60} \mathrm{Fe}_{30} \mathrm{Al}_{10-x} \mathrm{~B}_{x}(x=0,2.5,5,7.5$ and 10 at $\%)$ alloys with hard magnetic properties were prepared by an arc melting method. The bulk alloys have weights of 10 and $100 \mathrm{mg}$ with button shapes of 1 and $6 \mathrm{~mm}$ in thickness, respectively. The X-ray diffraction and TEM observation data reveal that the $\mathrm{Nd}_{60} \mathrm{Fe}_{30} \mathrm{Al}_{10}$ bulk alloy exhibits an amorphous phase while the other alloys consist of partial crystalline and amorphous phases. The bulk $\mathrm{Nd}_{60} \mathrm{Fe}_{30} \mathrm{Al}_{10}$ amorphous alloy of $1 \mathrm{~mm}$ in thickness exhibits crystallization temperature $\left(T_{\mathrm{x}}\right)$ of $802 \mathrm{~K}$, eutectic temperature $\left(T_{\mathrm{e}}\right)$ of $925 \mathrm{~K}$, and reduced crystallization temperature $\left(T_{\mathrm{x}} / T_{\mathrm{e}}\right)$ of 0.87 . The alloy exhibits hard magnetic properties at $298 \mathrm{~K}$, i.e., saturation magnetization of $0.13 \mathrm{~T}$, remanance of $0.09 \mathrm{~T}$, and intrinsic coercive filed of $275 \mathrm{kA} / \mathrm{m}$ under an applied field of $1242 \mathrm{kA} / \mathrm{m}$. These thermal and magnetic properties are nearly the same as those for the corresponding bulk amorphous cylinders of 1 to $12 \mathrm{~mm}$ in diameter prepared by copper mold casting. The replacement of $\mathrm{Al}$ with $\mathrm{B}$ in $\mathrm{Nd}-\mathrm{Fe}-\mathrm{Al}$ amorphous alloy causes a decrease in amorphous-forming ability (AFA), although their hard magnetic properties remain almost unchanged. The reason for the decrease in AFA was analyzed using mixing enthalpy $\left(\Delta H_{\text {mix }}\right)$ and mismatch entropy $\left(S_{\sigma}\right)$ corresponding the empirical criteria for the achievement of high AFA. Furthermore, amorphousforming composition regions (AFCRs) were calculated by giving a limitation for formation of an amorphous phase to $\Delta H_{\text {mix }}$ and $S_{\sigma}$ values, which arises from the statistics for 6500 amorphous alloys listed in a database. The calculated AFCR of the Nd-Fe-Al and Nd-Fe-B alloy systems agrees with the experimental data reported previously. The decrease in AFA by the replacement of $\mathrm{Al}$ with $\mathrm{B}$ in the $\mathrm{Nd}_{60} \mathrm{Fe}_{30} \mathrm{Al}_{10-x} \mathrm{~B}_{x}$ alloys is interpreted from the result that $\mathrm{Nd}_{60} \mathrm{Fe}_{30} \mathrm{~B}_{10}$ is located near the edge of the AFCR in Nd-Fe-B system.

(Received February 18, 2002; Accepted March 22, 2002)

Keywords: neodymium-iron-aluminum-boron system, bulk amorphous alloy, arc melting, hard magnetic properties, amorphous-forming ability, mixing enthalpy, mismatch entropy, amorphous-forming composition range

\section{Introduction}

Recently, bulk metallic glasses have been prepared in a number of multicomponent alloy systems consisting of ferrous and non-ferrous types. ${ }^{1)}$ The former type is represented by ferrous-group base multicomponent glasses, ${ }^{1)}$ and the latter is exemplified by $\mathrm{La}-, \mathrm{Zr}-, \mathrm{Pd}-, \mathrm{Cu}-$ and $\mathrm{Cu}$-based metallic glasses. ${ }^{1}$ As one group of ferrous non-crystalline alloys, one can list $\mathrm{Nd}-\mathrm{Fe}-\mathrm{Al}^{2,3)}$ and $\mathrm{Pr}-\mathrm{Fe}-\mathrm{Al}^{4)}$ amorphous alloys with hard magnetic properties. These lanthanide metal-iron based alloys are classified as amorphous alloys from the scientific definition because of the absence of glass transition point which is characteristic of metallic glasses. The other features of these amorphous alloys have been reported as follows: (1) high amorphous-forming ability (AFA) which enables us to fabricate the bulk amorphous alloys with a maximum diameter of $12 \mathrm{~mm},{ }^{3)}$ (2) significant change in magnetic properties with sample thicknesses. That is, the ribbon specimens with a thickness of approximately $20 \mu \mathrm{m}$ exhibit soft magnetism, while the bulk specimens exhibit hard magnetism with coercive force ranging 300 to $400 \mathrm{kA} / \mathrm{m}$ at room temperature, ${ }^{2-4)}$ (3) rather high reduced crystallization temperature $\left(T_{\mathrm{x}} / T_{\mathrm{e}}\right)$ of nearly $0.90^{2-4)}$ where $T_{\mathrm{x}}$ and $T_{\mathrm{e}}$ are onset temperature of crystallization and eutectic temperature, respectively.

As far as the fabrication methods for metallic glasses are concerned, the following solidification techniques have been reported: ${ }^{1)}$ water quenching, ${ }^{5-9)}$ arc-melt casting, ${ }^{10)}$ unidirectional melting, ${ }^{11)}$ suction casting, ${ }^{12-14)}$ squeeze casting, ${ }^{15)}$ clamp-melt casting, ${ }^{16)}$ centrifugal casting. ${ }^{17)}$ Among these fabrication methods, the conventional copper mold casting method has been most widely utilized for fabricating almost all bulk metallic glasses found to date. Other methods have been selected depending on glass-forming ability and demands of the shape and dimension of glassy alloys. For instance, the suction casting method was used for producing the $\mathrm{Nd}-\mathrm{Fe}-\mathrm{Al}$ bulk amorphous alloys with a diameter of $12 \mathrm{~mm} .{ }^{3)}$ The water-quenching method was used for large-scale $\mathrm{Pd}-\mathrm{Cu}-\mathrm{Ni}-\mathrm{P}$ metallic glasses, ${ }^{7,8)}$ and the clampmelt casting method ${ }^{16)}$ was developed for mass production of plate-shaped glasses. In the techniques developed for producing the bulk metallic glasses, the most convenient method is the arc-melt ${ }^{10)}$ which can be applied to $\mathrm{Zr}-\mathrm{Al}-\mathrm{Ni}-\mathrm{Cu}$ metallic glasses. Since the cooling rate of molten alloy in this method is lower than those in the others, the formation of the Zr-based bulk metallic glasses by this method is greatly attributable to high glass-forming ability of the Zr-based alloys. As described above, the $\mathrm{Nd}-\mathrm{Fe}-\mathrm{Al}$ amorphous alloys also have high AFA which enables us to fabricate bulk amorphous alloys up to $12 \mathrm{~mm}$ in diameter, and hence bulk amorphous alloys may be prepared by arc melting. In addition to the $\mathrm{Nd}-\mathrm{Fe}-\mathrm{Al}$ system, $\mathrm{Nd}-\mathrm{Fe}-(\mathrm{Al}, \mathrm{B})$ alloys with hard magnetic properties are expected to be formed in a bulk shape because $\mathrm{Al}$ and $\mathrm{B}$ belong to the same group in the periodical table.

The purposes of this paper are (1) to prepare $\mathrm{Nd}-\mathrm{Fe}-$ (Al, B) bulk amorphous alloys by arc melting, (2) to measure magnetic properties of the $\mathrm{Nd}-\mathrm{Fe}-(\mathrm{Al}, \mathrm{B})$ alloys, and (3) to investigate AFA in comparison with calculated amorphousforming composition ranges (AFCRs) of $\mathrm{Nd}-\mathrm{Fe}-\mathrm{Al}$ and $\mathrm{Nd}-$ $\mathrm{Fe}-\mathrm{B}$ systems.

\section{Methods}

\subsection{Experimental method}

Ternary alloys with compositions $\mathrm{Nd}_{60} \mathrm{Fe}_{30} \mathrm{Al}_{10-x} \mathrm{~B}_{x}(x=$ $0,2.5,5,7.5$ and 10 at $\%$ ) were prepared by arc melting a mix- 
ture of pure $\mathrm{Nd}, \mathrm{Fe}$ and $\mathrm{Al}$ metals and pure crystal B in an argon atmosphere. A pre-alloyed ingot of approximately $10 \mathrm{~g}$ in weight was crashed into fragments, and the pieces were subjected to subsequent arc melting to prepare a button-shaped alloy. Thus, the bulk alloys with weights of 10 and $100 \mathrm{mg}$ corresponding to about 1 and $6 \mathrm{~mm}$ in thickness, respectively, were obtained.

The structure of the bulk alloys was examined by X-ray diffractometry and TEM. The thermal stability associated with crystallization and other specific temperatures were examined at a heating rate of $0.67 \mathrm{~K} / \mathrm{s}$ by differential scanning calorimetry (DSC). Magnetization and coercive field under an applied field of $1242 \mathrm{kA} / \mathrm{m}$ were measured at room temperature with a vibrating sample magnetometer (VSM).

\subsection{Calculation method}

The calculation method of an amorphous-forming composition range (AFCR) was the same as the method used in previous studies. ${ }^{18,19)}$ In the calculation, the following five kinds of enthalpy terms were taken into account: enthalpies for chemical mixing $\Delta H^{\text {chem }}$, amorphous state $\Delta H^{\text {amor }}$, solid solutions $\Delta H^{\text {s.s }}$, topology $\Delta H^{\text {topological }}$ and elastic $\Delta H^{\text {elastic }}$. The definition formulae for $\Delta H^{\text {amor }}, \Delta H^{\text {s.s }}$ and $\Delta H^{\text {topological }}$ were given as eqs. (1) to (3). ${ }^{18-21)}$

$$
\begin{aligned}
& \Delta H^{\text {amor }}=\Delta H^{\text {chem }}(\text { amor })+\Delta H^{\text {topological }}, \\
& \Delta H^{\text {s.s }}=\Delta H^{\text {chem }}(\text { s.s })+\Delta H^{\text {elastic }},
\end{aligned}
$$

and

$$
\Delta H^{\text {topological }}=3.5 \sum_{i=1}^{3} c_{i} T_{\mathrm{m}}^{i} .
$$

Here, $c_{i}$ is the composition of the $i$-th element and $T_{\mathrm{m}}^{i}$ is its melting temperature. In eqs. (1) and (2), $\Delta H^{\text {chem }}$ was defined as eq. (4): the sum of the mixing enthalpy of the constituent binary subsystem $\Delta H_{i j}^{\text {chem }}$ with respect to the composition of the constituent elements based on the regular solution model. For a solid solution and an amorphous phase, $\Delta H_{i j}^{\text {chem }}$ was defined as eqs. (5) and (6), respectively, using the interfacial enthalpy $\Delta H^{\text {int }} \cdot{ }^{18,19)}$

$$
\begin{aligned}
& \Delta H^{\mathrm{chem}} \equiv \sum_{\substack{i=1 \\
i \neq j}}^{3} \Delta_{i j}^{\mathrm{chem}} c_{i} c_{j}, \\
& \Delta H_{i j}^{\mathrm{chem}}(\mathrm{s} . \mathrm{s})=x_{j}^{\mathrm{s}} \Delta H_{i \text { in } j}^{\mathrm{int}}+x_{i}^{\mathrm{s}} \Delta H_{j \text { in } i}^{\mathrm{int}}, \\
& \Delta H_{i j}^{\mathrm{chem}}(\text { amor })=f_{i}^{\mathrm{s}} \Delta H_{i \text { in } j}^{\mathrm{int}}+f_{j}^{\mathrm{s}} \Delta H_{j \text { in } i}^{\mathrm{int}} . \\
& x_{i}^{\mathrm{s}}=\frac{c_{i} V_{i}^{2 / 3}}{c_{i} V_{i}^{2 / 3}+c_{j} V_{j}^{2 / 3}}, \quad x_{j}^{\mathrm{s}}=1-x_{i}^{\mathrm{s}} . \\
& f_{i}^{\mathrm{s}}=x_{i}^{\mathrm{s}}\left\lfloor 1+5\left(x_{i}^{\mathrm{s}} x_{j}^{\mathrm{s}}\right)^{2}\right\rfloor .
\end{aligned}
$$

Here, $x_{i}^{\mathrm{s}}$ is the surface fraction and defined by eq. $(7)^{18-21)}$ with a molar volume of $i$-th atom $V_{i}$, which is taken from a previous study. ${ }^{21)}$ In eq. (8), $f_{i}^{\text {s }}$ is the degree to which $i$-th atoms are in contact with $j$-th atoms, ${ }^{20,21)}$ and the multiplying factor $\left[1+5\left(x_{i}^{\mathrm{s}} x_{j}^{\mathrm{s}}\right)^{2}\right]$ is due to the short-range order observed in the amorphous phase. ${ }^{22)}$
On the other hand, $\Delta H^{\text {elastic }}$ was calculated by eqs. (9) to (11). The elastic enthalpy term of a constituent binary subsystem $\Delta H_{i j}^{\text {elastic }}$ was defined as eq. $(10)^{18,19,21)}$ with elastic enthalpy of $i$-th element in $j$-th in the dilution limit $\Delta H_{i \text { in } j}^{\text {elas }}$ expressed by eq. (11). In eq. (11), bulk modulus $K$ and shear modulus $G$ were taken from a previous study, ${ }^{21)}$ and modified volumes $W_{i}$ and $W_{j}$ of a sphere $(i)$ and a hole $(j)$ due to internal stress were calculated on the basis of their definition formulae. ${ }^{21)}$ In accordance with the definition shown in eq. (2), $\Delta H^{\text {elastic }}$ was taken into account only for a solid solution. ${ }^{18,19,21)}$

$$
\begin{aligned}
\Delta H^{\text {elastic }} & \equiv \sum_{\substack{i=1 \\
i \neq j}}^{3} \Delta H_{i j}^{\text {elastic }} c_{i} c_{j}, \\
\Delta H_{i j}^{\text {elastic }} & =c_{j} \Delta H_{i \text { in } j}^{\text {elastic }}+c_{i} \Delta H_{j \text { in } i}^{\text {elastic }}, \\
\Delta H_{i \text { in } j}^{\text {elastic }} & =\frac{2 K_{i} G_{j}\left(W_{i}-W_{j}\right)^{2}}{4 G_{j} W_{i}+3 K_{i} W_{j}} .
\end{aligned}
$$

An amorphous phase was assumed to be formed at a composition where $\Delta H^{\text {amor }}<\Delta H^{\text {s.s }}$ using eqs. (1) and (2). ${ }^{18,19)}$ The parameters used for the calculation are summarized in Table 1.

\section{Results}

Figure 1 shows the X-ray diffraction patterns of the $\mathrm{Nd}_{60} \mathrm{Fe}_{30} \mathrm{Al}_{10-x} \mathrm{~B}_{x}(x=0,2.5,5,7.5$ and 10) alloys with a weight of $100 \mathrm{mg}$ (6 $\mathrm{mm}$ in thickness). The diffraction profile of the $\mathrm{Nd}_{60} \mathrm{Fe}_{30} \mathrm{Al}_{10}(x=0)$ alloy shows a broad pattern around $2 \theta$ from 20 to 40 degrees. Furthermore, no diffraction peaks resulting from a crystalline phas are seen over the entire diffraction angle. In contrast, appreciable diffraction peaks corresponding to $(004)_{\alpha-\mathrm{Nd}}$ and $(102)_{\alpha-\mathrm{Nd}}$ are dis-

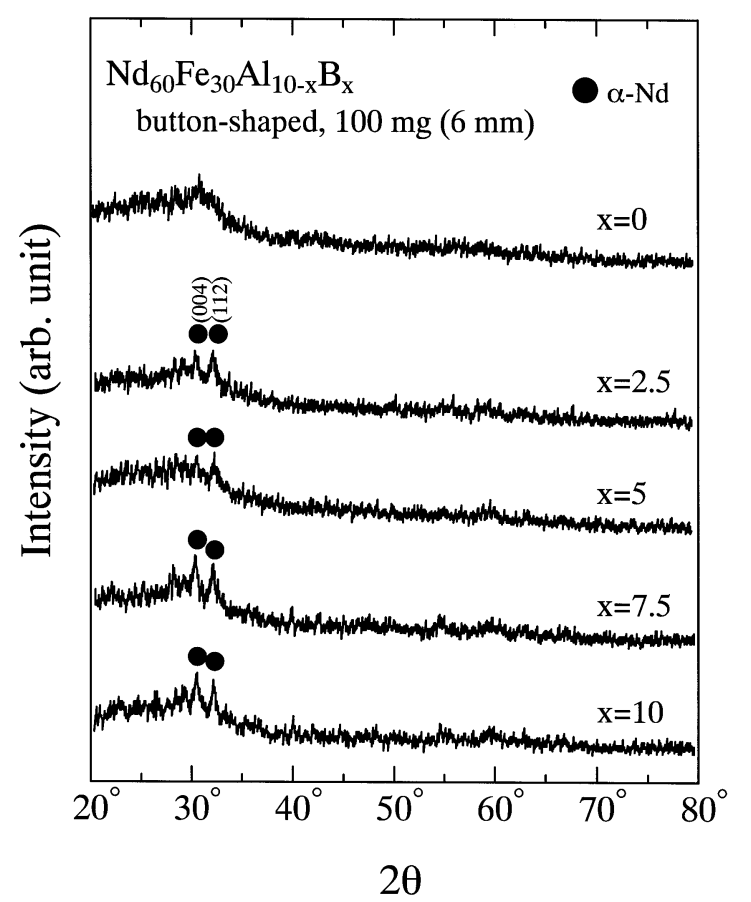

Fig. 1 X-ray diffraction patterns of $\mathrm{Nd}_{60} \mathrm{Fe}_{30} \mathrm{Al}_{10-x} \mathrm{~B}_{x}(x=0,2.5,5,7.5$ and 10) bulk alloys with a weight of $100 \mathrm{mg}$ ( $6 \mathrm{~mm}$ in thickness). 
Table 1 Interfacial enthalpy $\Delta H^{\text {int }}$ and elastic enthalpy $\Delta H^{\text {elastic }}$ for $\mathrm{Nd}_{60} \mathrm{Fe}_{30} \mathrm{Al}_{10}$ and $\mathrm{Nd}_{60} \mathrm{Fe}_{30} \mathrm{~B}_{10}$ alloys calculated in the present study.

\begin{tabular}{|c|c|c|c|c|c|c|c|c|c|c|c|c|}
\hline \multirow{2}{*}{$\begin{array}{l}\text { System } \\
\text { A-B-C }\end{array}$} & \multicolumn{6}{|c|}{$\Delta H_{i \text { in } j}^{\text {int }} / \mathrm{kJmol}^{-1}$} & \multicolumn{6}{|c|}{$\Delta H_{i \text { in } j}^{\text {elastic }} / \mathrm{kJmol}^{-1}$} \\
\hline & $A$ in $B$ & $\mathrm{~B}$ in $\mathrm{A}$ & $\mathrm{B}$ in $\mathrm{C}$ & $\mathrm{C}$ in $\mathrm{B}$ & $\mathrm{C}$ in $\mathrm{A}$ & $A$ in $C$ & $A$ in $B$ & $B$ in $A$ & $\mathrm{~B}$ in $\mathrm{C}$ & $\mathrm{C}$ in $\mathrm{B}$ & $\mathrm{C}$ in $\mathrm{A}$ & $\mathrm{A}$ in $\mathrm{C}$ \\
\hline $\mathrm{Al}-\mathrm{Fe}-\mathrm{Nd}$ & -48 & -41 & 2 & 4 & -184 & -127 & 12 & 19 & 121 & 87 & 43 & 56 \\
\hline $\mathrm{B}-\mathrm{Fe}-\mathrm{Nd}$ & -94 & -120 & 2 & 4 & -291 & -138 & 48 & 31 & 121 & 87 & 101 & 150 \\
\hline
\end{tabular}

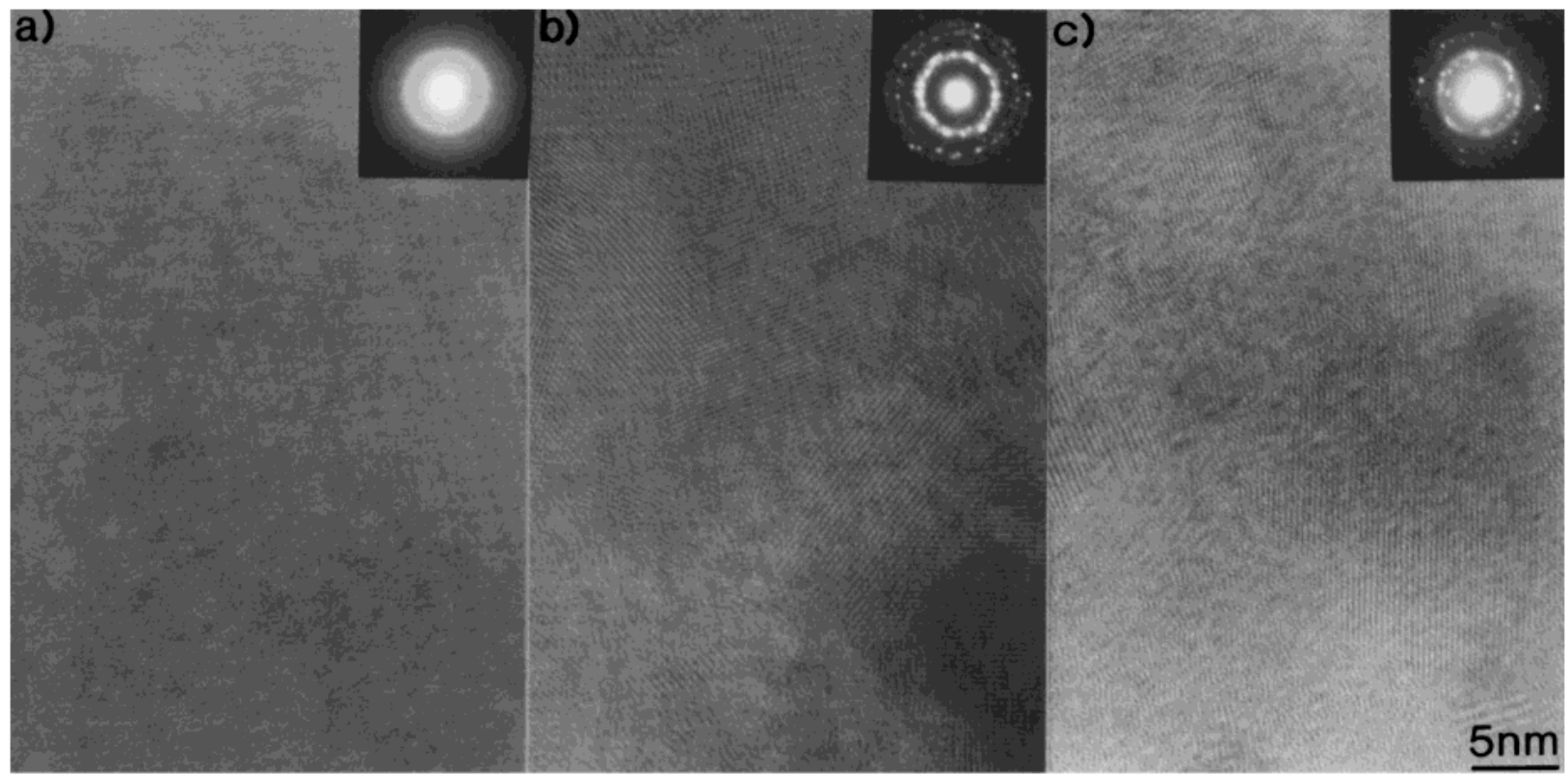

Fig. 2 High-resolution TEM images and selected area diffraction patterns (SADPs) taken from a part of approximately $100 \mathrm{~nm}$ in diameter for $\mathrm{Nd}_{60} \mathrm{Fe}_{30} \mathrm{Al}_{10-x} \mathrm{~B}_{x}(x=0,5$ and 10) bulk alloys with a weight of $10 \mathrm{mg}(1 \mathrm{~mm}$ in thickness $)$. a) $x=0$, b) $x=5$ and c) $x=10$.

cerned in the X-ray patterns of the B-containing alloys with $x=2.5,5,7.5$ and 10 . However, these diffraction profiles also show a rather broad peak around $2 \theta$ ranging from 20 to 40 degrees. Thus, Fig. 1 shows that the structure in the bulk $\mathrm{Nd}_{60} \mathrm{Fe}_{30} \mathrm{Al}_{10-x} \mathrm{~B}_{x}$ alloys is an amorphous phase for the $x=0$ alloy, and partially crystalline plus amorphous phases for the $x=2.5,5,7.5$ and 10 alloys. Figure 1 also indicates that the replacement of $\mathrm{Al}$ with $\mathrm{B}$ causes a decrease in AFA.

In order to examine in more details the structure of the button-shaped $\mathrm{Nd}-\mathrm{Fe}-\mathrm{Al}-\mathrm{B}$ alloys, TEM observations were carried out for the $\mathrm{Nd}_{60} \mathrm{Fe}_{30} \mathrm{Al}_{10-x} \mathrm{~B}_{x}(x=0,5$ and 10) alloys with a weight of $10 \mathrm{mg}$ ( $1 \mathrm{~mm}$ in thickness). Figure 2 shows the high-resolution TEM images, and selected-area electron diffraction patterns (SADPs) taken from a part of approximately $100 \mathrm{~nm}$ in diameter. Although the image in Fig. 2(a) contains some areas revealing a lattice fringe-like contrast, most parts in the image are occupied by non-periodic contrast. Furthermore, the SADP in Fig. 2(a) consists only of halo rings and no appreciable reflection spots from crystalline phases are seen. These results indicate that an amorphous phase is formed in this alloy. In contrast to Fig. 2(a), the images in Figs. 2(b) and (c) show distinct lattice fringes, and the corresponding SADPs give reflection spots. From the images shown in Figs. 2(b) and (c), the mean diameter of the lattice fringe regions is estimated as more than $20 \mathrm{~nm}$ for the $x=5$ alloy, and approximately $5 \mathrm{~nm}$ for the $x=10$ alloy. The difference in the region size for these alloys can be recognized in their SADPs as in the case of the difference in the number of the refrection spots: the spots in SADP are clearly observed in Fig. 2(b) than in Fig. 2(c). Furthermore, one can see halo ring in the SADPs, and the intensity of the halo rings is slightly higher in Fig. 2(c) than in Fig. 2(b). Thus, the result in Fig. 2 are consistent with the results obtained from the X-ray diffraction analysis, i.e., the structure of the $\mathrm{Nd}_{60} \mathrm{Fe}_{30} \mathrm{Al}_{10-x} \mathrm{~B}_{x}$ are an amorphous phase for the $x=0$ alloy, and partially crystalline plus amorphous phases for the $x=5$ and 10 alloys. The results of Figs. 1 and 2 indicate that AFA changes in the order of $\mathrm{Nd}_{60} \mathrm{Fe}_{30} \mathrm{Al}_{10}>\mathrm{Nd}_{60} \mathrm{Fe}_{30} \mathrm{~B}_{10}>\mathrm{Nd}_{60} \mathrm{Fe}_{30} \mathrm{Al}_{5} \mathrm{~B}_{5}$.

Figure 3 shows the DSC curves of the button-shaped $\mathrm{Nd}_{60} \mathrm{Fe}_{30} \mathrm{Al}_{10-x} \mathrm{~B}_{x}(x=0,2.5,5,7.5$ and 10) alloys with a weight of $10 \mathrm{mg}$ ( $1 \mathrm{~mm}$ in thickness). These alloys show the following three phase transitions: a distinct exothermic reaction due to crystallization marked with $T_{\mathrm{x}}$, an endothermic reaction due to eutectic reaction marked with $T_{\mathrm{e}}$, and melting marked with $T_{\mathrm{m}}$. From Fig. 3, $T_{\mathrm{x}}$ is measured as $790 \mathrm{~K}$ for $x=0,780 \mathrm{~K}$ for $x=2.5,820 \mathrm{~K}$ for $x=5,860 \mathrm{~K}$ for $x=7.5$ and $860 \mathrm{~K}$ for $x=10$. It is noted that the heat of the exothermic reaction tends to decrease with increasing $\mathrm{B}$ content, indicating a decrease in AFA of the alloys. However, one can discern an exothermic reaction in the DSC profile of the $x=10$ alloy. This indicates that the amorphous phase remains even in the highest $\mathrm{B}$ content alloy of 10 at $\%$.

Figure 4 shows the hysteresis $\mathrm{J}-\mathrm{H}$ loops of the buttonshaped $\mathrm{Nd}_{60} \mathrm{Fe}_{30} \mathrm{Al}_{10-x} \mathrm{~B}_{x}(x=0,2.5,5,7.5$ and 10) alloys with a weight of $10 \mathrm{mg}$ ( $1 \mathrm{~mm}$ in thickness). Smooth J-H curves without distinct step are seen for the $x=0,7.5$ and 10 


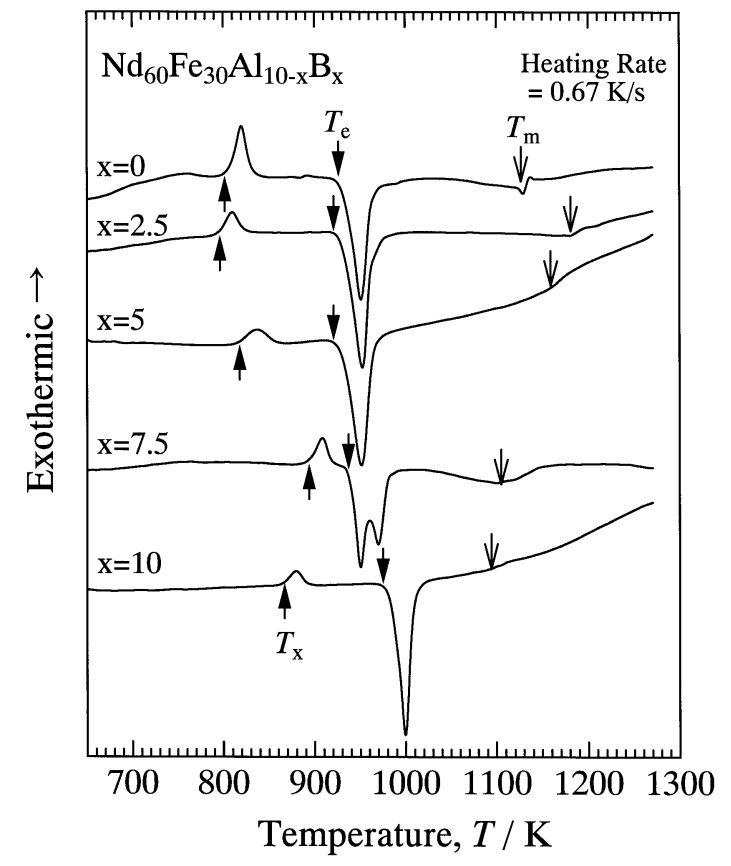

Fig. 3 DSC curves of bulk $\mathrm{Nd}_{60} \mathrm{Fe}_{30} \mathrm{Al}_{10-x} \mathrm{~B}_{x}(x=0,2.5,5,7.5$ and 10) bulk alloys with a weigh of $10 \mathrm{mg}$ ( $1 \mathrm{~mm}$ in thickness).

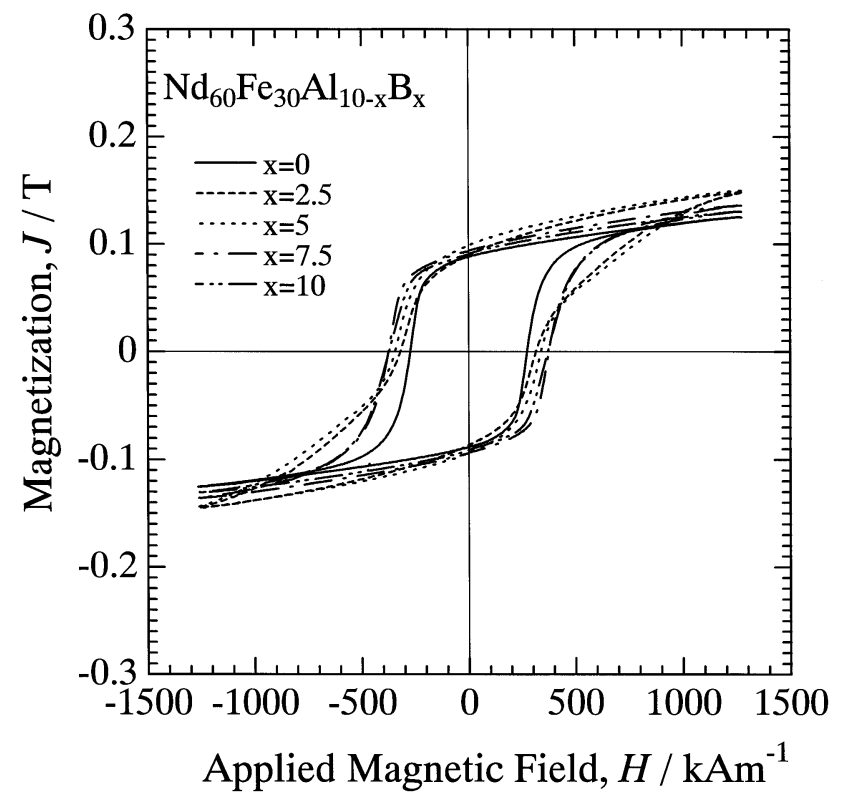

Fig. 4 Hysteresis J-H loops of the bulk $\mathrm{Nd}_{60} \mathrm{Fe}_{30} \mathrm{Al}_{10-x} \mathrm{~B}_{x}(x=0,2.5,5$, 7.5 and 10) alloys with a weight of $10 \mathrm{mg}$ (1 $\mathrm{mm}$ in thickness).

alloys. On the other hand, the J-H curves of the $x=2.5$ and 5 alloys show loose bending points at $(H, J) \approx( \pm 400 \mathrm{kA} / \mathrm{m}$, $\pm 0.03 \mathrm{~T})$. Furthermore, saturation magnetization $\left(J_{1242}\right)$ of the $x=2.5$ and 5 alloys are about $0.16 \mathrm{~T}$, which is higher than those of the other three alloys. Since it is widely accepted that magnetization increases when amorphous alloys crystallizes, these results suggest that rather coarse crystalline phases precipitate in the $x=2.5$ and 5 alloys. By the contrast, smooth J-H curves were measured for the $x=10$ alloy, although the X-ray diffraction and TEM observation results reveal the formation of amorphous and crystalline phases. The reason for the smooth $\mathrm{J}-\mathrm{H}$ curves for the $x=10$ alloy is presumably due to the rather small particle size of nearly $5 \mathrm{~nm}$, which was confirmed by TEM observation in Fig. 2. The fine mixed structure seems to enable a magnetic coupling between the amorphous and crystalline phases. From the J-H loops shown in Fig. 4, the remanance $\left(B_{\mathrm{r}}\right)$, magnetization under a field of $1242 \mathrm{kA} / \mathrm{m}\left(J_{1242}\right)$ and intrinsic coercive field $\left({ }_{\mathrm{i}} H_{\mathrm{c}}\right)$ are measured to be $0.076 \mathrm{~T}, 0.117 \mathrm{~T}$ and $292 \mathrm{kA} / \mathrm{m}$, respectively, for the bulk amorphous $\mathrm{Nd}_{60} \mathrm{Fe}_{30} \mathrm{Al}_{10}$ alloy. In comparison with those for the bulk amorphous $\mathrm{Nd}-\mathrm{Fe}-\mathrm{Al}$ alloys with a diameter of $1 \mathrm{~mm}\left(B_{\mathrm{r}}=0.112 \mathrm{~T}, J_{1432}=0.180 \mathrm{~T}\right.$ and $\left.{ }_{\mathrm{i}} H_{\mathrm{c}}=288 \mathrm{kA} / \mathrm{m}\right),{ }^{2)}$ and with a diameter of $12 \mathrm{~mm}$ $\left(B_{\mathrm{r}}=0.086 \mathrm{~T}, J_{1432}=0.117 \mathrm{~T}\right.$ and $\left.{ }_{\mathrm{i}} H_{\mathrm{c}}=321 \mathrm{kA} / \mathrm{m}\right),{ }^{3)}$ it can be said that almost the same magnetic properties were obtained in the button-shaped bulk specimen.

In order to confirm the AFA of the $\mathrm{Nd}-\mathrm{Fe}-\mathrm{Al}$ and $\mathrm{Nd}-\mathrm{Fe}-$ B systems theoretically, AFCR of the systems were calculated. Figure 5 shows the calculated AFCR of the $\mathrm{Nd}-\mathrm{Fe}-$ $\mathrm{Al}$ and $\mathrm{Nd}-\mathrm{Fe}-\mathrm{B}$ systems together with the experimental results. From Fig. 5, the calculated AFCRs extend a wide composition range over almost whole the composition range except the area near the constituent elements themselves. From Fig. 5, the calculated AFCR of $\mathrm{Nd}-\mathrm{Fe}-\mathrm{Al}$ system agrees with the experimental result. On the other hand, the calculated AFCR of Nd-Fe-B system is wider than the experimental result. Thus, these calculation results do not always provide a definite evidence which is useful for the interpretation of the difference in AFA between both the systems.

\section{Discussion}

In this section, we first discuss the decrease in AFA by the replacement of $\mathrm{Al}$ with $\mathrm{B}$, and subsequently the discrepancy in the AFCR of Nd-Fe-B system will be investigated.

As the necessary conditions for fabricating the metallic glasses, Inoue et al. proposed the following three criteria for the achievement of high glass-forming ability: ${ }^{1)}$ (1) multicomponent alloy systems consisting of more than three elements, (2) significant difference in atomic size ratios, above about $12 \%$, among the main three constituent elements, and (3) negative heats of mixing among their elements. In our previous study ${ }^{23,24)}$ we have also proposed the following thermodynamical functions which can deal with the second and third criteria numerically:

$$
\begin{aligned}
\Delta^{\text {chem }}= & \sum_{\substack{i=1 \\
i \neq j}}^{N} \Omega_{i j} c_{i} c_{j}, \\
S_{\sigma}= & k_{\mathrm{B}}\left[\frac{3}{2}\left(\zeta^{2}-1\right) y_{1}+\frac{3}{2}(\zeta-1)^{2} y_{2}\right. \\
& \left.-\left\{\frac{1}{2}(\zeta-1)(\zeta-3)+\ln \zeta\right\}\left(1-y_{3}\right)\right] .
\end{aligned}
$$

Here, $\Delta H^{\text {chem }}$ and $S_{\sigma}$ are the mixing enthalpy and the mismatch entropy, respectively, of the system. Equation (12) is similar to eq. (4); however, $\Omega_{i j}$ is the regular solution interaction parameter between $i$ - and $j$-elements, and has a constant value. ${ }^{23,24)}$ In eq. (13), $\zeta$ is defined as $\zeta=1 /(1-\xi)$, using packing fraction $\xi$. The dimensionless parameters, $y_{1}, y_{2}$ and $y_{3}$, have a relation of $y_{1}+y_{2}+y_{3}=1$, and are defined as eqs. (14) to (16) with atomic diameter $d_{i}$ of $i$-element. These 


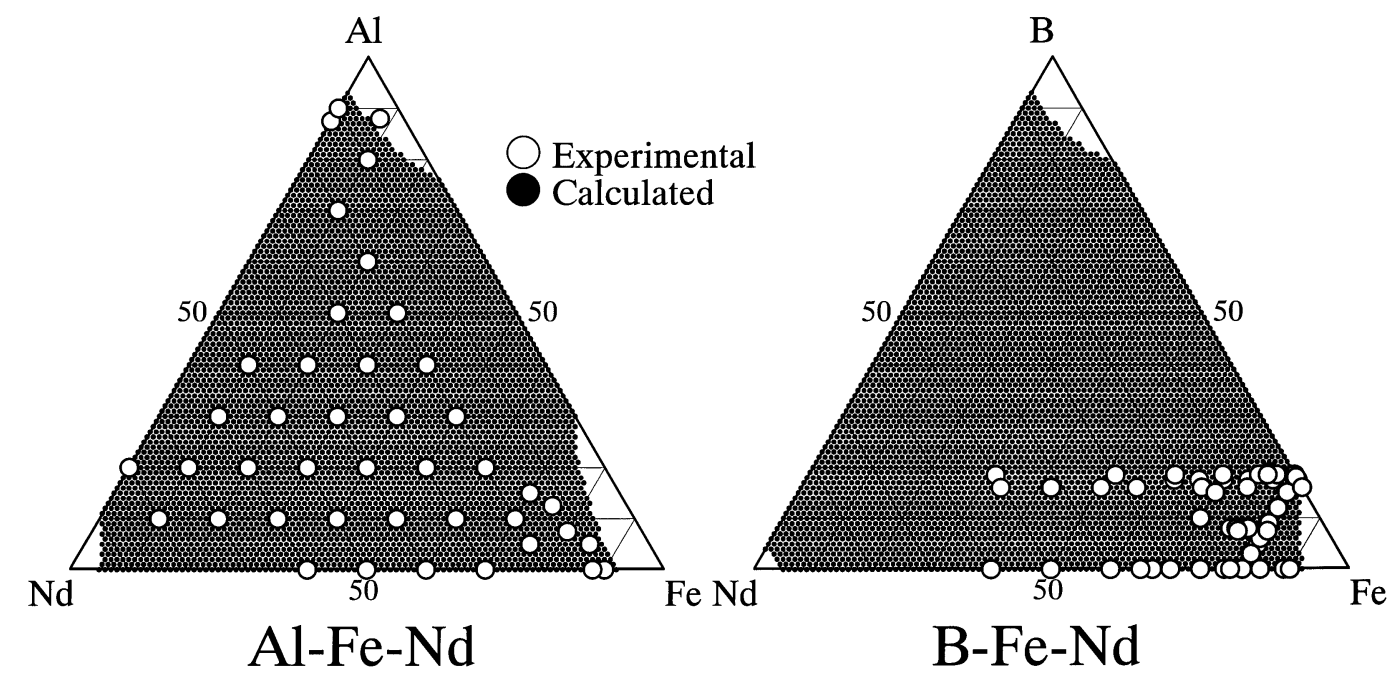

Fig. 5 Calculated amorphous-forming composition ranges (AFCRs) in $\mathrm{Nd}-\mathrm{Fe}-\mathrm{Al}$ and $\mathrm{Nd}-\mathrm{Fe}-\mathrm{B}$ systems. Experimental results ${ }^{2,27)}$ are also shown for comparison.

Table 2 Parameters used for the calculation of eqs. (12) and (13). Mixing enthalpy values $\Delta H_{\text {mix }}$ 's of three binary subsystems were calculated based on Miedema's macroscopic model. ${ }^{21)}$ The regular solution interaction parameter $\Omega_{i j}$ in eq. (12) has a relation with $\Delta H_{\text {mix }}$ as $\Omega_{i j}=4 \Delta H_{\text {mix }}$. Atomic radius $r$ was quoted from a databook. ${ }^{26)}$

\begin{tabular}{ccccccc}
\hline \multirow{2}{*}{$\begin{array}{c}\text { System } \\
\text { (A-B-C) }\end{array}$} & \multicolumn{3}{c}{$\Delta H_{\text {mix }} / \mathrm{kJ} \cdot \mathrm{mol}^{-1}$} & \multicolumn{3}{c}{$r / \mathrm{nm}$} \\
\hline Al-B & B-C & C-A & A & B & C \\
B-Fe-Nd & -11 & & -38 & 0.143 & 0.128 & 0.182 \\
\hline
\end{tabular}

equations were derived by transforming original formulae of Mansoori et al. ${ }^{25}$

$$
\begin{aligned}
y_{1} & =\frac{1}{\sigma^{3}} \sum_{j>i=1}^{n}\left(d_{i}+d_{j}\right)\left(d_{i}-d_{j}\right)^{2} c_{i} c_{j}, \\
y_{2} & =\frac{\sigma^{2}}{\left(\sigma^{3}\right)^{2}} \sum_{j>i=1}^{n} d_{i} d_{j}\left(d_{i}-d_{j}\right)^{2} c_{i} c_{j}, \\
y_{3} & =\frac{\left(\sigma^{2}\right)^{3}}{\left(\sigma^{3}\right)^{2}} \\
\sigma^{k} & =\sum_{i=1}^{n} c_{i} d_{i}^{k} ; k=2,3 .
\end{aligned}
$$

In calculating $\Delta H^{\text {chem }}$ and $S_{\sigma}$ by eqs. (12) and (13), packing fraction $\xi$ was fixed as 0.64 , which is assumed as dense random packing of non-crystalline materials. The parameters used for calculations are summarized in Table 2. Atomic radius $r$ was quoted from a databook. ${ }^{26)}$

By using eqs. (12) and (13), one can evaluate the degree of satisfaction of the three empirical component criteria as a function of alloy composition under the concept that the system with large and negative $\Delta H_{\text {mix }}$ and/or large $S_{\sigma} / k_{\mathrm{B}}$ has high AFA. The calculation results show $\left(\Delta H_{\text {mix }}, S_{\sigma} / k_{\mathrm{B}}\right)=$ $(-10 \mathrm{~kJ} / \mathrm{mol}, 0.46)$ for $\mathrm{Nd}_{60} \mathrm{Fe}_{30} \mathrm{Al}_{10}$, and $\left(\Delta H_{\text {mix }}, S_{\sigma} / k_{\mathrm{B}}\right)=$ $(-14 \mathrm{~kJ} / \mathrm{mol}, 0.62)$ for $\mathrm{Nd}_{60} \mathrm{Fe}_{30} \mathrm{~B}_{10}$. These calculation results indicate that the AFA of the $\mathrm{Nd}_{60} \mathrm{Fe}_{30} \mathrm{~B}_{10}$ alloy is higher than that of the $\mathrm{Nd}_{60} \mathrm{Fe}_{30} \mathrm{Al}_{10}$ alloy, in disagreement with the experimental results.

As far as $\Delta H_{\text {mix }}$ and $S_{\sigma} / k_{\mathrm{B}}$ values of amorphous alloys, statistic analyses were carried out for 6500 ternary amorphous alloys listed in a database. ${ }^{27)}$ As a result, alloys in an amorphous state have the threshold values ${ }^{23)}$ of $\Delta H_{\text {mix }}$ and $S_{\sigma} / k_{\mathrm{B}}$ which are surrounded in the following trapezoid region in $\Delta H_{\text {mix }}-\log \left(S_{\sigma} / k_{\mathrm{B}}\right)$ diagram as shown in Fig. 6:23) $-55 \mathrm{~kJ} / \mathrm{mol} \leq \Delta H_{\text {mix }} \leq 0 \mathrm{~kJ} / \mathrm{mol}$ and $\log (2 \times$ $\left.10^{-2}\right) \log \left(\Delta H_{\text {mix }} / 100+1\right) \leq \log \left(S_{\sigma} / k_{\mathrm{B}}\right) \leq 1$. The calculated results in the present study show that the $\mathrm{Nd}_{60} \mathrm{Fe}_{30} \mathrm{Al}_{10}$ amorphous alloy with $\left(\Delta H_{\text {mix }}, S_{\sigma} / k_{\mathrm{B}}\right)=(-10 \mathrm{~kJ} / \mathrm{mol}, 0.46)$ is located inside the trapezoid region while the $\mathrm{Nd}_{60} \mathrm{Fe}_{30} \mathrm{~B}_{10}$ alloy with $\left(\Delta H_{\mathrm{mix}}, S_{\sigma} / k_{\mathrm{B}}\right)=(-11 \mathrm{~kJ} / \mathrm{mol}, 0.62)$ lies near the upper edge of line of $\log \left(S_{\sigma} / k_{\mathrm{B}}\right)=1$. Since almost all of the amorphous alloys have been obtained in the trapezoid area of $\Delta H_{\text {mix }}$ and $S_{\sigma} / k_{\mathrm{B}}$ values, the sets the $\Delta H_{\text {mix }}$ and $S_{\sigma} / k_{\mathrm{B}}$ values plotted in the trapezoid region are thought to be a limitation factor for forming an amorphous phase. This limitation also implies that the AFA may be easier for $\mathrm{Nd}_{60} \mathrm{Fe}_{30} \mathrm{Al}_{10}$ than for $\mathrm{Nd}_{60} \mathrm{Fe}_{30} \mathrm{~B}_{10}$ because the $\mathrm{Nd}-\mathrm{Fe}-\mathrm{Al}$ alloy is located near the center in the trapezoid region. In order to relate the abovedescribed possibility with the AFA, the AFCR of $\mathrm{Nd}-\mathrm{Fe}-\mathrm{Al}$ and $\mathrm{Nd}-\mathrm{Fe}-\mathrm{B}$ systems were again calculated under the condition with imposing the limitation of the $\Delta H_{\text {mix }}$ and $S_{\sigma} / k_{\mathrm{B}}$ values. In the following calculation, the compositions whose $\Delta H_{\text {mix }}$ and $S_{\sigma} / k_{\mathrm{B}}$ were located outside the trapezoid area in Fig. 6 were excluded from the calculation results.

Figure 7 shows the calculated results for $\mathrm{Nd}-\mathrm{Fe}-\mathrm{Al}$ and $\mathrm{Nd}-\mathrm{Fe}-\mathrm{B}$ systems together with the statistical limitation of $\Delta H_{\text {mix }}$ and $S_{\sigma} / k_{\mathrm{B}}$ values. The calculations were carried out using the same parameters listed in Table 1. From Fig. 7, the calculated AFCR of $\mathrm{Nd}-\mathrm{Fe}-\mathrm{Al}$ system is similar to that in Fig. 5, indicating that the $\Delta H_{\text {mix }}$ and $S_{\sigma} / k_{\mathrm{B}}$ values of this system are located in the trapezoid area in Fig. 6. In strong contrast, the calculated AFCR of Nd-Fe-B system in Fig. 7 shows considerably smaller AFCR than that shown in Fig. 5. From Fig. 7(b), the $\mathrm{Nd}_{60} \mathrm{Fe}_{30} \mathrm{~B}_{10}$ alloy is located still inside the calculated AFCR, but its location is far away from the center, lies near the edge of the AFCR. This implies the decrease in AFA of the $\mathrm{Nd}_{60} \mathrm{Fe}_{30} \mathrm{~B}_{10}$ alloy. These calculation 


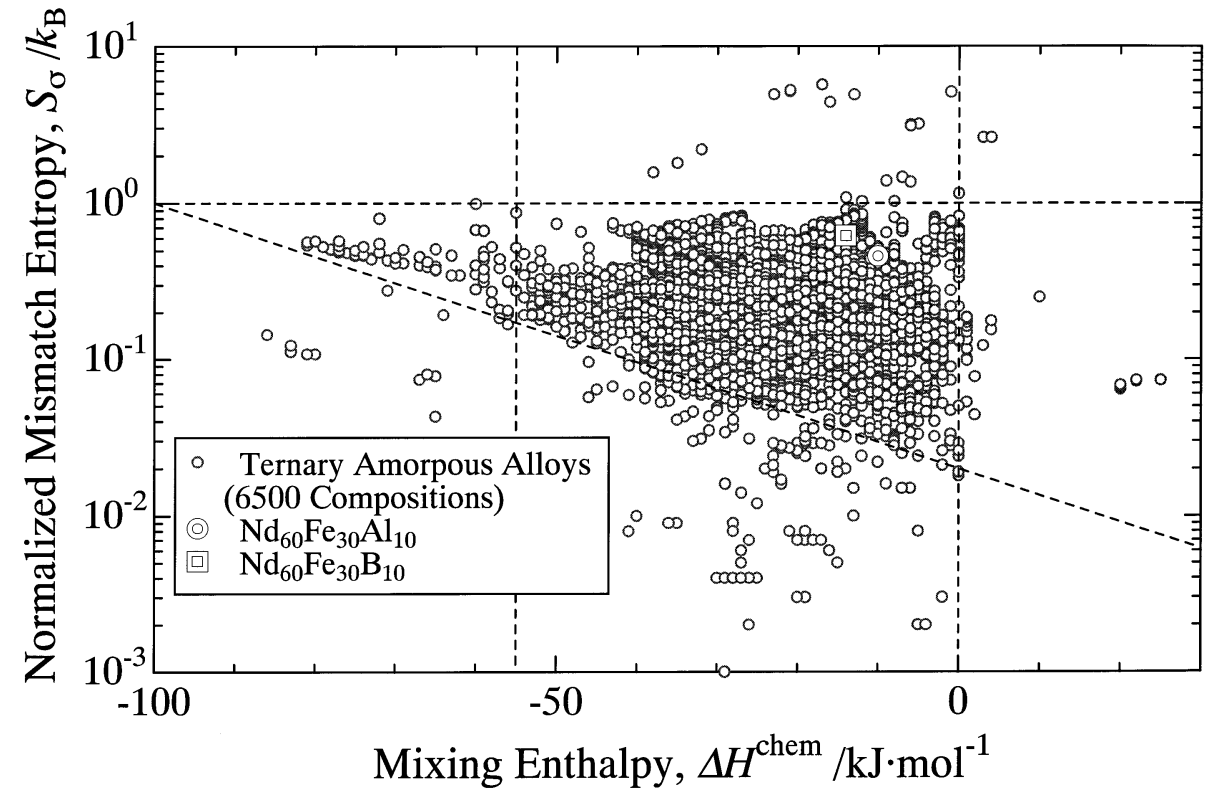

Fig. 6 Relation between $\Delta H^{\text {chem }}$ and $S_{\sigma} / k_{\mathrm{B}}$ for the 6500 amorphous alloys. $\Delta H^{\text {chem }}$ and $S_{\sigma} / k_{\mathrm{B}}$ for $\mathrm{Nd}_{60} \mathrm{Fe}_{30} \mathrm{Al}_{10}$ and $\mathrm{Nd}_{60} \mathrm{Fe}_{30} \mathrm{~B}_{10}$ alloys are plotted.

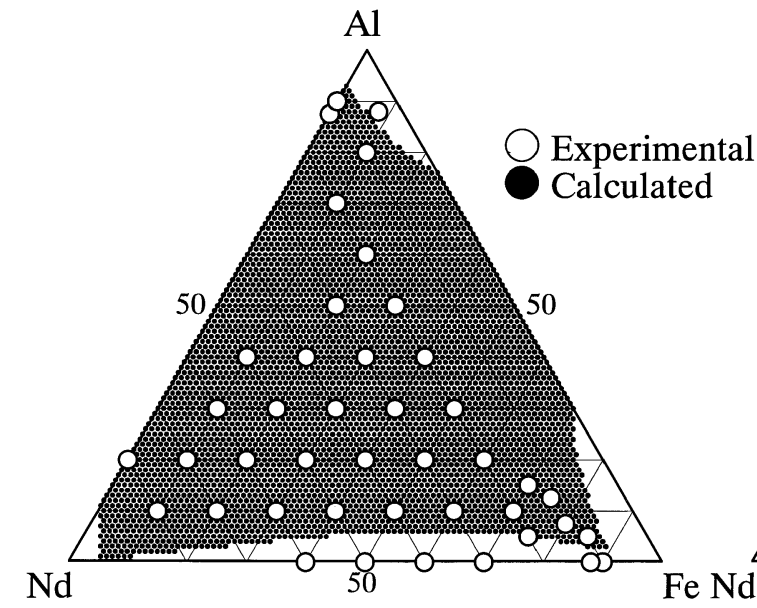

$\mathrm{Al}-\mathrm{Fe}-\mathrm{Nd}$

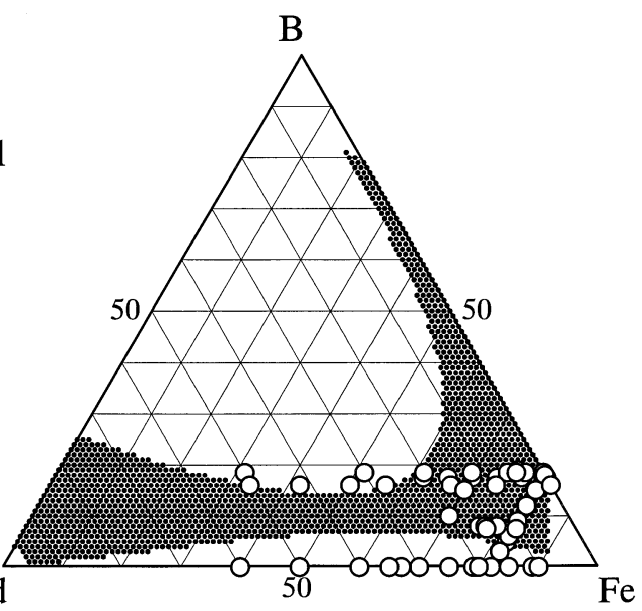

$\mathrm{B}-\mathrm{Fe}-\mathrm{Nd}$

Fig. 7 Calculated amorphous-forming composition ranges (AFCRs) in $\mathrm{Nd}-\mathrm{Fe}-\mathrm{Al}$ and $\mathrm{Nd}-\mathrm{Fe}-\mathrm{B}$ systems with a statistical limitation of $\Delta H_{\mathrm{mix}}$ and $S_{\sigma} / k_{\mathrm{B}}$ values of amorphous alloys. Experimental results ${ }^{2,27)}$ are also shown for comparison.

results provide us the reason for the decrease in AFA with replacement of $\mathrm{Al}$ with $\mathrm{B}$ in the $\mathrm{Nd}_{60} \mathrm{Fe}_{30} \mathrm{Al}_{10-x} \mathrm{~B}_{x}(x=0,2.5$, 5, 7.5 and 10) alloys.

Another factor for the difficulty of the amorphous phase formation for the $\mathrm{Nd}_{60} \mathrm{Fe}_{30} \mathrm{~B}_{10}$ alloy is presumably due to the presence of the intermetallic compounds in the ternary system. In the equilibrium the equilibrium ternary phase diagram ${ }^{28)}$ of $\mathrm{Nd}-\mathrm{Fe}-\mathrm{B}$ system, we can recognize nine compounds: $\mathrm{Nd}_{2} \mathrm{Fe}_{14} \mathrm{~B}, \mathrm{~B}_{3} \mathrm{FeNd}_{2}, \mathrm{~B}_{3} \mathrm{Fe}_{23} \mathrm{Nd}_{2}$, $\mathrm{B}_{4} \mathrm{Fe}_{4} \mathrm{Nd}, \quad \mathrm{B}_{6} \mathrm{Fe}_{2} \mathrm{Nd}_{5}, \mathrm{~B}_{18} \mathrm{Fe}_{18} \mathrm{Nd}_{5}, \mathrm{~B}_{3} \mathrm{Fe}_{7} \mathrm{Nd}_{2}, \quad \mathrm{~B}_{6} \mathrm{Fe}_{7} \mathrm{Nd}_{2}$ and $\mathrm{B}_{24} \mathrm{Fe}_{27} \mathrm{Nd}_{8}$. On the other hand, the $\mathrm{Nd}-\mathrm{Fe}-\mathrm{Al}$ system includes four compounds: $\mathrm{Al}_{2} \mathrm{Fe}_{15} \mathrm{Nd}_{2}, \mathrm{Al}_{8} \mathrm{Fe}_{4} \mathrm{Nd}$, $\mathrm{Al}_{45} \mathrm{Fe}_{45} \mathrm{Nd}_{10}$ and $\mathrm{Al}_{4} \mathrm{Fe}_{3} \mathrm{Nd}_{2}$. Although amorphous single phase alloys are formed in $\mathrm{Nd}-\mathrm{Fe}-\mathrm{B}$ systems by rapid quenching, the difference in numbers of intermetallic compound is thought to affect the AFA. This is also related to the experimental result that the AFA is lower for the $\mathrm{Nd}_{60} \mathrm{Fe}_{30} \mathrm{~B}_{10}$ alloy than for the $\mathrm{Nd}_{60} \mathrm{Fe}_{30} \mathrm{Al}_{10}$ alloy.

Finally, we describe advantage points of the arc melting method for the formation of amorphous alloys and metallic glasses. First, the button-shaped bulk specimens are prepared from the crashed fragments of an ingot, and hence, composition deviation of each specimens is considerably smaller as compared with the alloys prepared by the other methods. Second, the specimen size can be changed continuously because of no limitation of the mold size. Consequently, we can obtain amorphous alloys and metallic glasses in different relaxation states due to the difference in cooling rates of each specimen. These advantages can give ideal experimental conditions for the series of analyses of amorphous alloys and metallic glasses, in particular, in the field of physical properties which are strongly affected by structural relaxation. 


\section{Conclusions}

The conclusions derived from the present results and discussion are summarized as follows.

(1) Bulk $\mathrm{Nd}_{60} \mathrm{Fe}_{30} \mathrm{Al}_{10-x} \mathrm{~B}_{x}(x=0,2.5,5,7.5$ and $10 \mathrm{at} \%$ ) alloys with hard magnetic properties were prepared by the arc melting method. The $\mathrm{Nd}_{60} \mathrm{Fe}_{30} \mathrm{Al}_{10}$ alloy has an amorphous phase, and the other alloys consist of partially crystalline plus amorphous phases.

(2) The bulk $\mathrm{Nd}_{60} \mathrm{Fe}_{30} \mathrm{Al}_{10}$ amorphous alloy of $1 \mathrm{~mm}$ in thickness has crystallization temperature $\left(T_{\mathrm{x}}\right)$ of $802 \mathrm{~K}$ and eutectic temperature $\left(T_{\mathrm{e}}\right)$ of $925 \mathrm{~K}$, and reduced crystallization temperature $\left(T_{\mathrm{x}} / T_{\mathrm{e}}\right)$ of 0.87 .

(3) The bulk $\mathrm{Nd}_{60} \mathrm{Fe}_{30} \mathrm{Al}_{10}$ amorphous alloy exhibits hard magnetic properties at $298 \mathrm{~K}$ : saturation magnetization of $0.13 \mathrm{~T}$, remanance of 0.09 , and intrinsic coercive filed of $275 \mathrm{kA} / \mathrm{m}$.

(4) The thermal and magnetic properties are nearly the same as those for the corresponding bulk amorphous cylinders with diameters of 1 to $12 \mathrm{~mm}$ prepared by conventional casting.

(5) The replacement of $\mathrm{Al}$ with $\mathrm{B}$ in $\mathrm{Nd}-\mathrm{Fe}-\mathrm{Al}$ amorphous alloy causes a decrease in amorphous-forming ability (AFA) with remaining hard magnetic properties.

(6) The reason for the decrease in AFA by the replacement of $\mathrm{Al}$ with $\mathrm{B}$ in the $\mathrm{Nd}_{60} \mathrm{Fe}_{30} \mathrm{Al}_{10-x} \mathrm{~B}_{x}$ alloys is presumably because the $\mathrm{Nd}_{60} \mathrm{Fe}_{30} \mathrm{~B}_{10}$ alloy is locateed near the edge of the AFCR in $\mathrm{Nd}-\mathrm{Fe}-\mathrm{B}$ system.

\section{REFERENCES}

1) A. Inoue: Bulk Amorphous Alloys-Preparation and Fundamental Characteristics-, Materials Science Foundations 4, (Trans Tech Publications, Netherlands, 1998) pp. 1-116.

2) A. Inoue, T. Zhang, W. Zhang and A. Takeuchi: Mater. Trans., JIM 37 (1996) 99-108.

3) A. Inoue, T. Zhang, A. Takeuchi and W. Zhang: Mater. Trans., JIM 37
(1996) 636-640.

4) A. Inoue, T. Zhang and A. Takeuchi: Mater. Trans., JIM 37 (1996) 1731-1740.

5) A. Inoue, T. Zhang, E. Matsubara, Y. Waseda and T. Masumoto: Mater. Trans., JIM 32 (1991) 201-206.

6) A. Inoue, K. Kita, T. Zhang and T. Masumoto: Mater. Trans., JIM 30 (1989) 722-725.

7) A. Inoue, N. Nishiyama and T. Matsuda: Mater. Trans., JIM 37 (1996) $181-184$.

8) A. Inoue, N. Nishiyama and H. M. Kimura: Mater. Trans., JIM 38 (1997) 179-183.

9) K. Amiya and A. Inoue: Mater. Trans. 42 (2001) 543-545.

10) A. Inoue, T. Shibata and T. Zhang: Mater. Trans., JIM 36 (1995) 14201426.

11) Y. Yokoyama and A. Inoue: Mater. Trans., JIM 36 (1995) 1398-1402.

12) A. Inoue and T. Zhang: Mater. Trans., JIM 36 (1995) 1184-1187.

13) A. Inoue and T. Zhang: Mater. Trans., JIM 37 (1996) 185-187.

14) A. Inoue, T. Zhang, A. Takeuchi and W. Zhang: Mater. Trans., JIM 37 (1996) 636-640.

15) T. Zhang and A. Inoue: Mater. Trans., JIM 39 (1998) 1230-1237.

16) H. Fukumura, A. Inoue, H. Koshiba and T. Mizushima: Mater. Trans. 42 (2001) 1820-1822.

17) T. Zhang A. Inoue: Mat. Res. Soc. Symp. Proc. 644 (2001) L.12.24.1L.12.24.6.

18) A. Takeuchi and A. Inoue: Mater. Trans., JIM 42 (2001) 1435-1444.

19) B. S. Murty, S. Ranganathan and M. M. Rao: Mater. Sci. Eng. A149 (1992) 231-240.

20) H. Bakker, G. F. Zhow and H. Yang: Prog. Mater. Sci. 39 (1995) 159_ 241.

21) H. Bakker: Enthalpies in Alloys, Materials Science Foundations 1, (Trans Tech Publications, Netherlands, 1998) pp. 1-78.

22) A. W. Weber: J. Phys. F: Metal Phys. 17 (1987) 809-814.

23) A. Takeuchi and A. Inoue: Mater. Trans., JIM 41 (2000) 1372-1378.

24) A. Takeuchi and A. Inoue: Mater. Sci. Eng. A304-306 (2001) 446-451.

25) G. A. Mansoori, N. F. Carnahan, K. E. Starling and T. W. Leland, Jr.: J. Chem. Phys. 54 (1971) 1523-1525.

26) Metals Reference Book, 5th ed. (eds. C. J. Smithells and E. A. Brandes 1976, Butterworths) p. 994.

27) Y. Kawazoe, T. Masumoto, K. Suzuki, A. Inoue, J.-Z. Yu, T. Aihara Jr., T. Nakanomyo and A. P. Tsai: Nonequilibrium Phase Diagrams of Ternary Amorphous Alloys, LB: New Ser., Group III: Condensed, Vol. 37: ed., (Springer, 1997 pp. 1-295).

28) Handbook of Ternary Alloy Phase Diagrams (ed. P. Villars, A. Prince and H. Okamoto, ASM 1995) pp. 1-10998. 